\title{
Les voyages d'Alexandre au paradis: Orient et Occident, regards croisés, C. Gaullier-Bougassas et M. Bridges (dir.)
}

\section{G. Matteo Roccati}

\section{(2) OpenEdition}

Journals

Édition électronique

URL : http://journals.openedition.org/studifrancesi/9874

DOI : 10.4000/studifrancesi.9874

ISSN : 2421-5856

Éditeur

Rosenberg \& Sellier

\section{Édition imprimée}

Date de publication : 1 août 2017

Pagination : 331-332

ISSN : 0039-2944

\section{Référence électronique}

G. Matteo Roccati, «Les voyages d'Alexandre au paradis: Orient et Occident, regards croisés, C. GaullierBougassas et M. Bridges (dir.) », Studi Francesi [En ligne], 182 (LXI | II) | 2017, mis en ligne le 18 octobre 2017, consulté le 06 janvier 2021. URL : http://journals.openedition.org/studifrancesi/9874 ; DOI : https://doi.org/10.4000/studifrancesi.9874

Ce document a été généré automatiquement le 6 janvier 2021.

\section{cc) (†)}

Studi Francesi è distribuita con Licenza Creative Commons Attribuzione - Non commerciale - Non opere derivate 4.0 Internazionale. 


\title{
Les voyages d'Alexandre au paradis: Orient et Occident, regards croisés, $C$. Gaullier-Bougassas et M. Bridges (dir.)
}

\author{
G. Matteo Roccati
}

\section{RÉFÉRENCE}

Les voyages d'Alexandre au paradis: Orient et Occident, regards croisés, sous la direction de Catherine GAULLIER-BOUGASSAS et Margaret BRIDGES, Turnhout, Brepols, 2013, «Alexander redivivus» $3,548 \mathrm{pp}$.

1 L'ambition de l'ouvrage est de «placer les récits des voyages d'Alexandre au paradis, si nombreux et si divers, dans les multiples contextes culturels et littéraires qui leur ont prêté senefiance, interpréter cette senefiance au regard de la spécificité de chaque œuvre, et aussi retracer les chemins tortueux parcourus par les motifs récurrents jusqu'à leur point de rencontre, sinon de départ» (p. 11). Après un article introductif (Catherine GAULLIER-BOUGASSAS et Margaret BRIDGES, Sur les traces d'une légende, en quête du sens, pp. 5-11), une première section «propose un premier parcours des textes et tente de retracer l'apparition puis la transmission et les métamorphoses des trois séquences majeures autour de la fontaine d'immortalité, du pays des Bienheureux et du paradis terrestre» (p. 10). On y trouvera les contributions suivantes: Catherine GAULLIER-BOUGASSAS, Quêtes d'immortalité ou de salut: des origines grecque et hébraique aux réinterprétations orientales, pp. 15-45, et La pierre du paradis et son enseignement dans les cuvres latines et romanes, pp. 47-59; Margaret BRIDGES, Figurations d'une rencontre dans les littératures germaniques, néerlandaise et anglaise, pp. 61-75; Catherine GAULLIER-BOUGASSAS et Margaret BRIDGES, Avatars et imitations: la création de nouvelles fictions paradisiaques, pp. 77-90. 
2 Les contributions des autres sections traitent des différentes traditions. Aires juive, arabe, persane: Jean-Pierre RоTнSCHILD, L'«Iter ad Paradisum» entre homélie rabbinique, roman, traité d'apologétique et «exemplum», pp. 93-125; René вLосн, Alexandre le Grand et le judaïsme: la double stratégie d'auteurs juifs de l'Antiquité et du Moyen Âge, pp. 147-164; Marco DI BRANCO, Alessandro/Dū 'l-Qarnayn, il paradiso e la fonte della vita nella letteratura araba medievale, pp. 127-146; Émilie PICHEROT, Le paradis interdit dans le «Rrekontamiento del rrey Ališand're»: étude du statut non prophétique d'Alexandre le musulman, pp. 353-375; Mario CASARI, Un lieu de traduction: Alexandre au paradis dans la tradition persane, pp. 379-403; Marina GAILLARD, D'un bout du monde à l'autre: lieux paradisiaques et terres ultimes dans le roman d'Alexandre en prose de l'Iran classique, pp. 405-445. Aire française: Catherine GAULLIER-BOUGASSAS, Les eaux troublées de la quête d'Alexandre et les sources orientales du «Roman d'Alexandre» français: fontaine de vie, fleuve de mort et paradis terrestre, pp. 165-210; Hélène BELLON-MÉGUELLE, Les imprévus du voyage: le voyage d'Alexandre au paradis terrestre dans la littérature française de la fin du Moyen Âge, pp. 275-296; Jean-Claude MÜHLETHALER, Échec amoureux et échec politique: le remploi du "Voyage au paradis» dans le "Chevalier errant" de Thomas III de Saluces, pp. 447-461. Aire germanique: Christophe THIERRY, L'épisode du voyage au paradis dans le "Straßburger Alexander» (fin du XII ${ }^{e}$-début du XIII siècle), pp. 239-274. Aires anglaise et écossaise: Margaret BRIDGES, Five Late Middle English Versions of the Narreme of Alexander's Wondrous Gift, pp. 485-519; Anna CAUGHEY et Emily WINGFIELD, Conquest and Imperialism: Medieval Scottish Contexts for Alexander's «Journey to Paradise», pp. 463-484. Aire russe: Elena KoRoleva, Les Brahmanes et le paradis dans les romans d'Alexandre russes, pp. 297-351. Un article traite de la présence dans les mappemondes de références aux conquêtes et explorations d'Alexandre, de la signification morale de la représentation de la terre qui se trouve dans le roman, enfin du sens théologique des images de la mappemonde d'Ebstorf: Patrick GAUTIER DALCHÉ, Quatre notes sur Alexandre et la cartographie médiévale, pp. 213-238. Index des noms des auteurs et des oeuvres aux pp. 531-541. 